\title{
Bacteriemia por Shigella flexneri serotipo 6 en pacientes con SIDA. Presentación de dos casos clínicos
}

\author{
Patricia Hitateguy, Leticia Caiata, María I. Mota, Cristina Bazet y Gustavo Varela
}

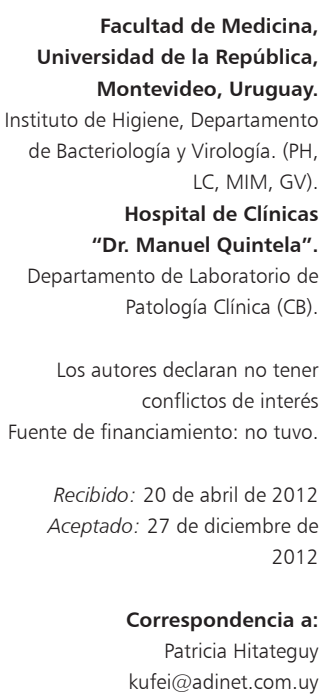

Facultad de Medicina, Universidad de la República,

Montevideo, Uruguay. Instituto de Higiene, Departamento de Bacteriología y Virología. ( $\mathrm{PH}$, LC, MIM, GV)

Hospital de Clínicas

"Dr. Manuel Quintela".

Departamento de Laboratorio de

Patología Clínica (CB)

Los autores declaran no tener conflictos de interés

Fuente de financiamiento: no tuvo.

Recibido: 20 de abril de 2012 Aceptado: 27 de diciembre de

Correspondencia a:

Patricia Hitateguy kufei@adinet.com.uy

\section{Introducción}

L os patógenos entéricos constituyen la segunda causa de morbilidad y mortalidad en el mundo. Los niños bajo 5 años de edad y los individuos con algún tipo de inmunodepresión constituyen los principales grupos de riesgo $^{1,2}$.

En personas infectadas con el virus de la inmunodeficiencia humana (VIH) la diarrea es una causa reconocida de morbilidad y mortalidad. Su incidencia es 20 a 100 veces mayor que en la población general y representa el segundo motivo de consulta en los servicios de salud. La diarrea ocurre en algún momento de la enfermedad en $60 \%$ de los pacientes que viven en países industrializados y hasta en $90 \%$ de los pacientes que habitan en países en desarrollo ${ }^{3-5}$.

En todo el mundo, las especies de Shigella se encuentran entre los patógenos entéricos más prevalentes, constituyendo una de las principales causas de disentería. Se estima que anualmente ocurren alrededor de 163 millones de episodios de infección por Shigella spp. en países en vías de desarrollo, con un millón de muertes ${ }^{2,6,7}$.

En personas con infección con VIH, Shigella spp. también se encuentra entre los patógenos bacterianos frecuentemente asociados a episodios de diarrea junto a Campylobacter spp. y Salmonella spp $^{3,8}$.

La bacteriemia por Shigella es una complicación que ocurre con baja frecuencia en individuos sanos. Un metaanálisis de los trabajos publicados en África sugiere que menos de $1 \%$ de las bacteriemias en este continente se deben a Shigella spp. ${ }^{9}$. Si bien la bacteriemia y la enfermedad sistémica por Shigella spp. han sido reconocidas como un problema en niños en países en desarrollo, desde el advenimiento de la pandemia del VIH los casos en adultos se reconocen con mayor frecuencia.

En un estudio realizado en África (donde la tasa de seroprevalencia de VIH es alta) entre 2003 y 2009, la incidencia de shigelosis invasora fue de 0,11 a 0,13 por 100.000 habitantes. La letalidad fue de $29 \%$ y las personas infectadas con VIH tuvieron 4,1 veces más probabilidades de morir que las no infectadas por VIH ( $p<0,008$; IC $1,05$ a 11,08$)^{2}$.

Se presentan dos casos de bacteriemia por Shigella flexneri que ocurrieron simultáneamente en una institución pública de asistencia médica en dos pacientes adultos con SIDA.

\section{Caso clínico 1}

Varón de 42 años de edad y oficio pintor, procedente de un medio socio-económico bajo. Tenía antecedentes de infección por VIH diagnosticada 7 años antes, nunca acudió a control ni recibió terapia anti-retroviral (TARV). Consultó en el servicio de emergencia por deposiciones líquidas (hasta 6 episodios al día), sin sangre, mucus ni pus. Presentaba una baja de peso de aproximadamente 20 $\mathrm{kg}$ en los últimos 4 meses. No presentó fiebre, vómitos ni dolor abdominal. En el examen físico el paciente estaba vigil, eupneico, afebril, normotenso (120/80) y con una 
FC de 95 por min; además se constató en mal estado general, con intensa palidez de piel y mucosas. Se internó con diagnóstico clínico de diarrea en paciente con SIDA.

De los exámenes de laboratorio destacaban: hemoglobina $8,5 \mathrm{~g} / \mathrm{dl}$; hematocrito $26,2 \%$; volumen corpuscular medio (VCM) 75,4 fl y hemoglobina corpuscular media (HCM) 22,8 pg; leucocitos $4.500 / \mathrm{mm}^{3}$; linfocitos: $670 /$ $\mathrm{mm}^{3}$ (15\%), recuento de linfocitos CD4: 100 céls $/ \mathrm{mm}^{3}$ y VHS: $120 \mathrm{~mm} / 1^{\circ}$ hora. En el examen directo de deposiciones se observó la presencia de abundantes leucocitos PMN y en el cultivo hubo desarrollo de Shigella sp. En los dos hemocultivos tomados hubo aislamiento de Shigella sp.

\section{Caso clínico 2}

Varón de 33 años de edad, de oficio clasificador de residuos. Su pareja en ese momento tenía antecedente de infección por VIH y no utilizaba métodos de barrera.

Consultó en el servicio de emergencia por deposiciones líquidas de hasta 7 episodios al día, sin sangre, mucus ni pus; acompañadas de dolor abdominal y sin fiebre. Presentaba una baja de peso de aproximadamente $15 \mathrm{~kg}$ en 3 meses. En el examen físico el paciente estaba vigil, afebril, normotenso (120/70), con una FC de 82 por min, pálido y en mal estado general. A las $24 \mathrm{~h}$ presentó fiebre de hasta $38,5^{\circ} \mathrm{C}$ axilar y heces líquidas con sangre y mucus en varias oportunidades. Fue internado en la misma sala que el primer paciente, con diagnóstico clínico de diarrea en paciente con probable infección por VIH.

De los exámenes de laboratorio destacaban: hemoglobina 9,8 g/dl; hematocrito: $28,3 \%$; VCM 77,2 fl y

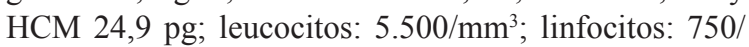
$\mathrm{mm}^{3}$ (17,1\%); recuento de linfocitos CD4 150 céls/ mm 3 ; VHS: $69 \mathrm{~mm}$ en $1^{\circ}$ hora. El examen directo de deposiciones mostró la presencia de abundantes PMN y en el coprocultivo se desarrolló Shigella sp. así como en los dos hemocultivos.

La serología para VIH fue reactiva y se confirmó por técnica de Western blot en el Laboratorio de Referencia Nacional.

\section{Estudios bacteriológicos}

Las cepas se enviaron al Departamento de Bacteriología y Virología, Instituto de Higiene, para completar su estudio. La identificación de género se confirmó por métodos fenotípicos convencionales utilizando los siguientes medios de identificación: triple azúcar hierro (TSI), movilidad-indol-ornitina decarboxilasa (MIO), citrato de Simmons, fenilalanina deaminasa, agar hierrolisina (LIA), arginina dehidrolasa, utilización de mucato, malonato y fermentación de carbohidratos en caldo con rojo-fenol ${ }^{10}$.

El serogrupo de las cepas de Shigella se determinó por la técnica de aglutinación en lámina utilizando antisueros policlonales comerciales (BD, Difco ${ }^{\mathrm{TM}}$ ) y el serotipo con antisueros absorbidos serotipo-específicos.

Para el estudio de la susceptibilidad antimicrobiana se utilizó la técnica de difusión en disco en $\operatorname{agar}^{11}$. Los antibacterianos ensayados fueron: ampicilina, ampicilina/sulbactam, cefradina, cefoxitina, ceftriaxona, ácido nalidíxico, ciprofloxacina, tetraciclina y cotrimoxazol (Oxoid Ltd., Basingstoke, Hampshire, Inglaterra). No se realizó evaluación de la sensibilidad a azitromicina debido a que no existen puntos de corte para la interpretación de las pruebas de susceptibilidad por esta técnica para azitromicina en EUCAST ni en CLSI ${ }^{11}$.

La electroforesis en gel en campo pulsado (PFGE) de los cuatro aislados de Shigella spp. se realizó de acuerdo al procedimiento estándar del CDC ${ }^{12}$. La interpretación de los patrones de bandas se realizó visualmente siguiendo los criterios de Tenover y cols ${ }^{13}$.

Las cuatro cepas correspondieron a Shigella flexneri del serotipo 6 y presentaron resistencia sólo a cotrimoxazol. Las dos cepas recuperadas del mismo paciente (heces y sangre) mostraron un patrón de bandas idéntico entre sí y muy similar al patrón obtenido con las cepas del otro paciente (Figura 1). Las cepas se definieron como muy relacionadas desde el punto de vista genético.

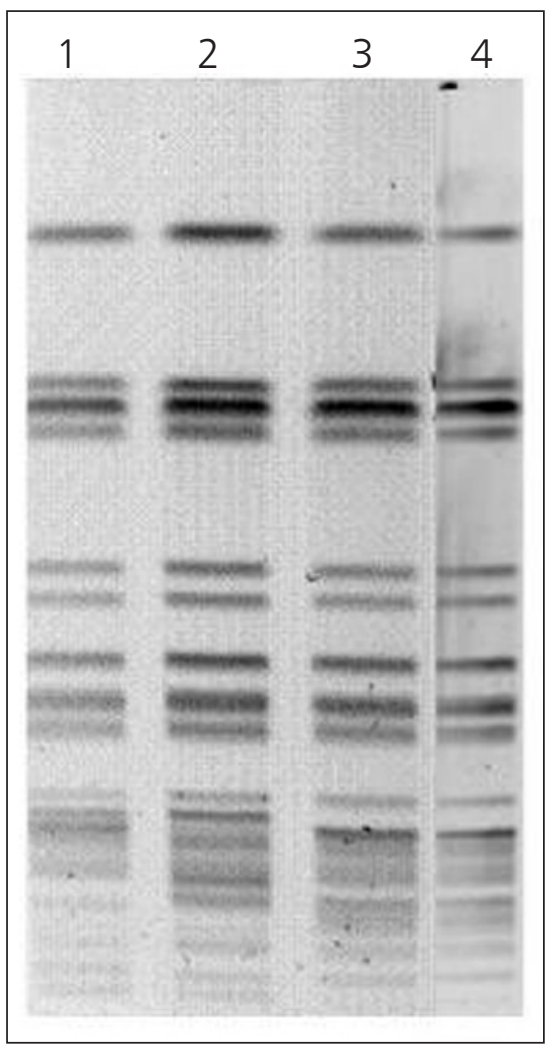

Figura 1. Patrón de bandas de las cepas de Shigella flexneri serotipo 6 obtenidos por PFGE luego de la digestión del ADN cromosómico con la enzima Xbal. Carril 1, cepa IH1 aislada de las heces del paciente 1; carril 2, cepa IH2 aislada a partir del hemocultivo del paciente 1 ; carril 3, cepa IH3 aislada de las heces del paciente 2 y carril 4, cepa IH4 aislada del hemocultivo del paciente 2 . 


\section{Tratamiento antimicrobiano y evolución}

El primer paciente recibió cotrimoxazol, $800 / 160 \mathrm{mg}$, vía oral, cada $12 \mathrm{~h}$, por $48 \mathrm{~h}$. Luego de conocer el resultado bacteriológico el tratamiento se cambió a ampicilina $1 \mathrm{gr}$ iv, 4 veces al día, durante 6 días, y luego ciprofloxacina $500 \mathrm{mg}$ vía oral, cada $12 \mathrm{~h}$, hasta completar 14 días de tratamiento.

El segundo paciente se mantuvo sin tratamiento antimicrobiano hasta el resultado bacteriológico. Recibió ciprofloxacina $400 \mathrm{mg}$ iv, dos veces al día, por 7 días y luego $500 \mathrm{mg}$ vía oral, dos veces al día, hasta completar 14 días de tratamiento.

En ambos casos la evolución fue favorable con remisión de la sintomatología digestiva y sin aparición de otras complicaciones, por lo que fueron dados de alta.

\section{Discusión}

Esta es la primera comunicación regional de episodios de bacteriemia por Shigella spp. en adultos con SIDA. La búsqueda de artículos con contenido similar se hizo en SCIELO y PubMed utilizando la combinación de palabras clave: Shigella, bacteriemia y VIH.

Previamente habíamos observado esta entidad en dos niños bajo 5 años de edad con desnutrición grave que ingresaron a la emergencia del hospital pediátrico por diarrea sanguinolenta (datos no publicados). En 2006, Ayala y cols. comunicaron un episodio de bacteriemia por Shigella flexneri en una niña de 4 años sin antecedentes patológicos ${ }^{14}$.

El paciente 1 tenía una infección conocida por $\mathrm{VIH}$, sin TARV y con un recuento de CD4 en el momento del ingreso de 100 céls $/ \mathrm{mm}^{3}$. El paciente 2 no tenía el antecedente de infección por VIH, diagnóstico que se realizó durante su internación. Resultó altamente sospechoso el antecedente de su pareja y el hecho de haber presentado una bacteriemia por Shigella spp. En ese sentido, Frías y cols., comunicaron un caso de bacteriemia por S. flexneri en una mujer cuyo diagnóstico coincidió con el de infección por VIH en estadio SIDA ${ }^{15}$.

Ambos pacientes negaron tener un vínculo epidemiológico previo al ingreso y no se registraron casos de diarrea en otros pacientes internados en ese mismo período en el servicio de emergencia, lo que alejó la posibilidad de un brote de origen común. La hipótesis propuesta fue que el paciente 2 había adquirido la infección a partir del paciente 1. A favor de esta situación estaban los siguientes elementos: el paciente 1 había ingresado antes, los dos estuvieron internados en la misma sala de emergencia, el paciente 2 desarrolló el cuadro disentérico 18-24 h después de su ingreso, las cepas recuperadas fueron del mismo serotipo e idéntico antibiotipo y resultaron muy relacionadas desde el punto de vista genético por $X b a \mathrm{I}$ PFGE. Sin embargo, no pudimos establecer el modo de transmisión. La unidad de emergencia del Hospital de Clínicas tiene 11 camas de pre-internación separadas por material liviano con dos baños, uno para hombres y otro para mujeres. Dispone además de una sala de aislamiento con baño privado y un área de cuidados especiales con cuatro camas y baño aparte. Los dos pacientes estuvieron ingresados en el área de pre-internación, compartiendo el baño hasta su ingreso a sala general. Esta situación puede haber favorecido la transmisión, sumado a la inmunosupresión por la infección por VIH. No pudimos descartar la posibilidad de que la transmisión haya ocurrido por vía sexual. Está bien establecido que la shigelosis se trasmite de esta forma en hombres que tienen sexo con hombres ${ }^{16}$.

Con respecto a las características microbiológicas de las cepas carecemos de resultados previos de aislados de $S$. flexneri recuperados de adultos con gastroenteritis. En un estudio realizado en nuestro país que incluyó 50 cepas de Shigella flexneri recuperadas de coprocultivos de niños bajo 5 años con diarrea sanguinolenta, la resistencia antimicrobiana encontrada fue de $60 \%$ para ampicilina y $36 \%$ para cotrimoxazol. La distribución de serotipos fue: $34(68 \%)$ de los aislados correspondieron al serotipo 2a; $9(18 \%)$ al serotipo $3 \mathrm{c} ; 2(4 \%)$ al serotipo $4 ; 2$ (4\%) al serotipo 6 y $2(4 \%)$ al serotipo 1 . Una cepa resultó no tipificable. Las dos cepas del serotipo 6 fueron resistentes a cotrimoxazol y sensibles a ampicilina ${ }^{17}$.

En otro estudio posterior que también incluyó niños bajo 5 años, encontramos que $81 \%$ de los aislados de $S$. flexneri mostraron resistencia a ampicilina y $35 \%$ a cotrimoxazol ${ }^{6}$.

Strey y cols., comunicaron que $65,3 \%$ de las cepas de Shigella spp. recuperadas en países de Latinoamérica fueron resistentes a cotrimoxazol. El porcentaje fue similar en cepas de Shigella spp. procedentes de Europa, Israel y Turquía ${ }^{18}$. El estudio no incluyó cepas de Uruguay, por lo tanto se necesitan estudios complementarios realizados en adultos con VIH/SIDA y diarrea para conocer la prevalencia de resistencia a diferentes antimicrobianos en patógenos entéricos locales.

La bacteriemia por Shigella spp. es una complicación potencialmente fatal en pacientes con SIDA que debe ser diagnosticada rápidamente y tratada en forma adecuada.

En pacientes inmunocomprometidos con diarrea que requieren internación se recomienda la realización de hemocultivos ya que presentan un riesgo mayor de desarrollar una bacteriemia por agentes como Salmonella, Shigella y Campylobacter spp. De acuerdo a los resultados comunicados por Streit y cols. y Gomi y cols., la elección inicial de fluoroquinolonas sería adecuada; sin embargo, hay que tener en cuenta que la presencia de cepas de Salmonella y Shigella spp. resistentes a ácido nalidíxico puede generar fallas de tratamiento cuando se utilizan las dosis habituales de fluoroquinolonas. Además cabe destacar que $42 \%$ de las cepas de Campylobacter 
spp. recuperadas en Latinoamérica fueron resistentes a ciprofloxacina $^{18,20}$.

Por último, es importante conocer los perfiles de susceptibilidad locales a los antimicrobianos de estos agentes para poder comenzar con un tratamiento empírico adecuado y también disponer de los resultados de PFGE para complementar los datos de la epidemiología tradicional; en este caso la PFGE permitió establecer que las cepas de ambos pacientes estaban muy relacionadas desde el punto de vista genético.

Agradecimientos. Al Profesor Felipe Schelotto por su colaboración en la redacción del escrito.

\section{Resumen}

Las infecciones por Shigella spp., en general, permanecen localizadas en el tracto digestivo y tienen una evo- lución autolimitada. La bacteriemia es una complicación potencialmente letal que ocurre en pacientes con algún tipo de inmunocompromiso. Presentamos dos casos de bacteriemia causadas por Shigella en dos adultos con SIDA. En ambos pacientes, se recuperó Shigella flexneri en muestras de deposiciones y sangre. Los aislados correspondieron al serotipo 6 , fueron resistentes sólo a cotrimoxazol y mostraron un perfil de bandas similar por PFGE. Los pacientes recibieron tratamiento antimicrobiano prolongado y la evolución fue favorable. No se registraron otros casos de diarrea en individuos admitidos en el servicio de emergencia. La hipótesis fue que el paciente 2 adquirió la infección en el hospital a partir del paciente 1. Sin embargo, no pudimos establecer el modo de transmisión. Aunque poco frecuente, es importante tener presente la ocurrencia de bacteriemia por Shigella spp. o por otros enteropatógenos bacterianos en pacientes inmunocomprometidos con diarrea.

\section{Referencias bibliográficas}

1.- Kosek M, Bern C, Guerrant R L. The global burden of diarrhoeal disease, as estimated from studies published between 1992 and 2000. Bull World Health Org 2003; 81 : 197-204.

2.- Keddy K H, Sooka A, Crowther-Gibson P, Quan V, Meiring S, Cohen C, et al. Systemic shigellosis in South Africa. Clin Infect Dis 2012; 54: 1448-54.

3.- Sanchez T H, Brooks J T, Sullivan P S, Juhasz M, Mintz E, Dworkin M S, et al. Bacterial diarrhea in persons with HIV infection, United States, 1992-2002. Clin Infect Dis 2005; 41: 1621-7.

4.- Mathews W C, McCutchan J A, Asch S, Turner B J, Gifford A L, Kuromiya K, et al. National estimates of HIV-related symptom prevalence from the HIV Cost and Services Utilization Study. Med Care 2000; 38: 750-62.

5.- Weber R, Ledergerber B, Zbinden R, Altwegg M, Pfyffer G E, Spycher M A, et al. Enteric infections and diarrhea in human immunodeficiency virus-infected persons: prospective community-based cohort study. Swiss HIV Cohort Study. Arch Intern Med 1999; 159: 1473-80.

6.- Mota M I, Gadea M P, González S, González G, Pardo L, Sirok A et al. Bacterial pathogens associated with bloody diarrhea in Uruguayan children. Rev Argent Microbiol 2010; 42: 114-7.

7.- Kotloff K, Winickoff J P, Ivanoff B, Clemens J D, Swerdlow D L, Sansonetti P J, et al. Global burden of Shigella infections: implications for vaccine development and implementation of control strategies. Bull World Health Org 1999; 77: 651-66.

8.- Angulo F J, Swerdlow D L. Bacterial enteric infections in persons infected with human immunodeficiency virus. Clin Infect Dis 1995; 21: S84-93.

9.- Reddy E A, Shaw A V, Crump J A. Communityacquired bloodstream infections in Africa: a systematic review and meta-analysis. Lancet Infect Dis 2010; 10: 417-32.

10.- Ewing W H. Edwards and Ewing's, editors. Identification of Enterobacteriaceae. 4th ed. New York: Elsevier, 1980 p. 137-72.

11.- CLSI. Performance Standards for Antimicrobial Susceptibility Testing; 20th Informational Supplement. CLSI document M100-S20. Wayne, PA: Clinical and Laboratory Standards Institute; 2010.

12.- Centers for Disease Control and Prevention. Standardized molecular subtyping of foodborne bacterial pathogens by pulsed field gel electrophoresis: a manual. Atlanta: National Center for Infectious Diseases; 1996 (updated 2000).

13.- Tenover F C, Arbeit R D, Goering R V, Mickelsen P A, Murray B E, Persing D H, et al. Interpreting chromosomal DNA restriction patterns produced by pulsedfield gel electrophoresis: criteria for bacterial strain typing. J Clin Microbiol 1995; 33: 2233-9.

14.- Ayala S, Moreno R P, Araguas J L, Caprotta CG, Pena R M. Shock séptico por Shigella flexneri. Arch Argent Pediatr 2006; 104: 351-3.
15.- Frías J A, Hernández S, Molina F J, García M G. Bacteriemia por Shigella flexneri en mujer con VIH/SIDA. Enf Infec Microbiol 2006; 26 (1).

16.- Morgan O, Crook P, Cheasty T, Jiggle B, Giraudon I, Hughes H, et al. Shigella sonnei outbreak among homosexual men, London. Emerg Infect Dis 2006; 12: 1458-60.

17.- Mota M I, Varela G, Gadea M P, Caffer M I, Sirok A, Schelotto F. Serotipos, perfil plasmídico y antibiotipos en cepas de Shigella flexneri aisladas de niños menores de 5 años con diarrea sanguinolenta usuarios de los servicios de Salud Pública. Rev Med Uruguay 2005; 21 : 30-6.

18.- Streit J M, Jones R N, Toleman M A, Stratchounski L S, Fritsche T R. Prevalence and antimicrobial susceptibility patterns among gastroenteritis-causing pathogens recovered in Europe and Latin America and Salmonella isolates recovered from bloodstream infections in North America and Latin America: report from the SENTRY Antimicrobial Surveillance Program (2003). Int J Antimicrob Agents 2006; 27: 367-75.

19.- Huebner J, Czerwenka W, Gruner E, von Graevenitz A. Shigellemia in AIDS patients: case report and review of the literature. Infection 1993; 21: 122-4.

20.- Gomi H, Jiang Z D, Adachi J A, Ashley D, Lowe B, Verenkar M P, et al. In vitro antimicrobial susceptibility testing of bacterial enteropathogens causing traveler's diarrhea in four geographic regions. Antimicrob Agents Chemother 2001; 45: 212-6. 